Orthopäde 2009 • 38:870-870

DOI 10.1007/s00132-009-1552-1

๑) Springer Medizin Verlag 2009

\section{W.M. Strobl}

Abteilung für Orthopädie des Kindes- und Jugendalters,

Orthopädisches Spital Wien-Speising, Wien

\title{
Erratum zu: Hüftgelenk bei neuromuskulären Erkrankungen
}

\section{Der Orthopäde (2009) 38:643-654}

In diesem Beitrag wurde in der $\bullet$ Abb. 2 die Strecke b nicht korrekt wiedergegeben. Wir bitten, dies zu entschuldigen und die korrigierte Abbildung zu berücksichtigen.

\section{Korrespondenzadresse}

Dr.W.M. Strobl

Abteilung für Orthopädie des Kindes- und Jugendalters, Orthopädisches Spital WienSpeising

Speisinger Straße 109, A-1130 Wien

Österreich

walter.strobl@oss.at
Abb. $2>$ Bestimmung der Dezentrierung durch den Migrationsindex (Ml) nach Reimers

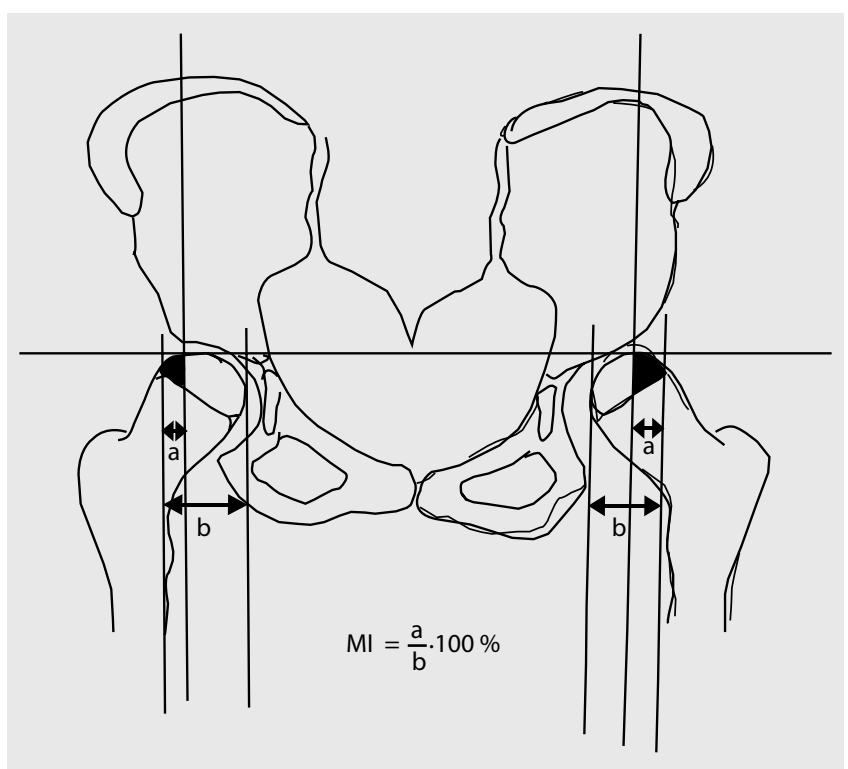

